\title{
ARTICLE
}

\section{A HYDROMETALLURGICAL PROCESS FOR THE RECOVERY OF CERIUM FROM KHUREN KHAD ORE}

\author{
Sandagdorj N. *, Enerel B., Ching-Hwa Lee, Gankhuyag E. and Terbish N.
}

Environmental Engineering Department, Da-Yeh University, Dacun Changhua, Taiwan

ARTICLE INFO: Received: 19 Feb, 2019; Accepted: 15 Apr, 2019

\begin{abstract}
This study presents the recovery of cerium (Ce) from Khuren Khad ore by using the hydrometallurgical process. Several methods of leaching and precipitation were employed to investigate the recovery efficiency of Ce from the ore. According to the result, it is $4.8 \%$ of Ce contained in this ore sample. The best result of this study reveals that 100\% Ce leaching efficiency can be obtained under leaching conditions of $6 \mathrm{~N} \mathrm{HCl}$ at a temperature of $70^{\circ} \mathrm{C}$ and $5 \mathrm{~g} / 50 \mathrm{~mL}$ solid/liquid ratio and $3 \mathrm{~h}$. Further, $99.60 \%$ precipitation recovery of Ce was achieved with $\mathrm{NaHCO}_{3}$ at an interval of 24 hours. After leaching and precipitation, the concentration of Ce was enriched from $4.8 \%$ of Khuren Khad ore to $33.09 \%$ of precipitation product.
\end{abstract}

Keywords: Recovery; leaching; precipitation; cerium; Khuren Khad ore;

\section{INTRODUCTION}

Rare earth elements (REE) are a group of 17 similar elements important in the manufacture of many high technologies. According to the U.S. Geological Survey, the global reserves of rare earth are approximately 120 million metric tons [1]. Today, China alone has been producing more than $90 \%$ of REEs globally. Different metallurgical, chemical, catalytic, electrical, magnetic and optical properties of the REEs have led to an ever-increasing variety of applications. According to researches, Ce is used in catalysts, gas mantles, flat-screen televisions, low-energy light bulbs, magneticoptic compact discs and as a glass polishing agent [2, 3]. Continuous development of advanced technologies over the past decades has created increasing demand for REEs, with global emphasis on identifying new alternate sources to ensure adequate supply $[4,5]$.

Many studies have written about leaching recovery of REE containing materials by thermal and chemical methods [6-10]. However, very few reports are available on the leaching recovery of natural ore [11-13]. As compared to pyro-metallurgical operations, leaching is cheaper and more flexible. Acid leaching is a common industrial practice for the recovery of metals from ore. Furthermore, Ce contained in the leaching solution can be recovered by precipitation [14-15]. 
The main objective of this study is to develop a sustainable and coherent process for the recovery of Ce from Khuren Khad ore. In the present study, the Khuren Khad ore was

\section{MATERIALS AND METHODS}

\section{Sample collection and chemicals}

The sample subjected to experimental studies was representatively collected from Mushgia Khudag REE deposit, Mongolia. Leaching reagents of $\mathrm{H}_{2} \mathrm{SO}_{4}(95-97 \%$, GR reagent grade), $\mathrm{HNO}_{3}(65 \%$, GR reagent grade) and $\mathrm{HCl}(37 \%$, GR reagent grade) were purchased from Merck Company. All experiments were conducted with deionised water.

\section{Composition analysis}

The concentration of Ce was determined by Taiwan EPA's established heavy metal digestion method (NIEA S321.63B) using

$$
\text { Leaching recovery }(\%)=\frac{W_{1}}{W_{2}} \times 100 \% \text {; }
$$

where $W_{1}$ is the weight of metal leached, and is the weight of metal contained in the sample.

\section{Precipitation}

Precipitation is also a commonly used method to remove metal ions from solutions. Ce recovered from the precipitation of the best leaching solution and its precipitation efficiency were investigated. Since Ce readily forms precipitation complex with carbonate obtained from the Mushgia Khudag deposit in southern Mongolia, which is one of the highgrade ores of REEs in the Mushgia Khudag deposit, Mongolia.

inductively coupled plasma-atomic emission spectrometry (ICP-AES) through [16].

\section{Leaching}

Leaching is a widely used common industrial hydrometallurgical technique for the recovery of metals from ore and other materials. Leaching recovery of Ce from Khüren Khad ore by using $\mathrm{HNO}_{3}, \mathrm{H}_{2} \mathrm{SO}_{4}$, and $\mathrm{HCl}$ acids were examined. Leaching conditions, including leaching time, the concentration of leaching reagent, temperature, andsolid/liquid ratio, were explored in this study. The percentage of leaching recovery was calculated using Eq (1):

and sulfate ions, $\mathrm{NH}_{4} \mathrm{HCO}_{3}, \mathrm{NaHCO}_{3}$, $\mathrm{Na}_{2} \mathrm{SO}_{4}$, and $\mathrm{K}_{2} \mathrm{SO}_{4}$ were used as precipitating agents. In these precipitate tests, $20 \mathrm{~mL}$ of Ce containing leaching solution was added to the precipitation reagent in 1:1 liquid/liquid ratio and the reaction mixture was kept for 24 hours at a room temperature of $27^{\circ} \mathrm{C}$. The resulting solution was analysed by ICP-AES and the precipitation efficiency was calculated Eq (2):

$$
\text { Precipitation recovery }(\%)=\frac{W_{b}-W_{a}}{W_{b}} \times 100 \%
$$

where $W_{b}$ is the weight of metal in solution before precipitation and $W_{a}$ is the weight of the metal in solution after precipitation.

\section{RESULTS AND DISCUSSION}

\section{Sample composition analysis}

The Khuren Khad ore was ground and sieved to less than 50 mesh size. The sample was composed mainly of Ce and its composition was analysed using ICP-AES. The content of $\mathrm{Ce}$ in the collected Khuren Khad ore was $4.8 \%$. 


\section{Leaching}

To optimize the leaching conditions, tests were conducted with leaching reagents, namely $\mathrm{HCl}, \mathrm{H}_{2} \mathrm{SO}_{4}$ and $\mathrm{HNO}_{3}$ under various experimental conditions, such as temperature, concentration, solid/liquid ratio and time. Figure 1 shows the leaching recovery of $\mathrm{Ce}$ at $70^{\circ} \mathrm{C}$, the concentration of leaching reagent $1 \mathrm{~N}$ and solid/liquid ratio of $1 \mathrm{~g} / 50 \mathrm{~mL}$. As shown in this graph, the leaching recovery of $\mathrm{Ce}$ with $\mathrm{HCl}$ was higher than those with $\mathrm{H}_{2} \mathrm{SO}_{4}$ and $\mathrm{HNO}_{3}$. Therefore, further leaching recovery experiments were set up with $\mathrm{HCl}$ with varying concentration levels from $1 \mathrm{~N}$ to
$5 \mathrm{~N}$ for $3 \mathrm{~h}$ with $1 \mathrm{~g} / 50 \mathrm{~mL}$ of solid/liquid ratio and varying solid/liquid ratio from $1 \mathrm{~g} / 50 \mathrm{~mL}$ to $5 \mathrm{~g} / 50 \mathrm{~mL}$; the results are shown in Figure 2 and Figure 3 respectively. As can be seen from the graphs, the leaching recovery of Ce increased significantly with the increase of the acid solution concentration, while there was a slight increase with an increase in the solid/liquid ratio. According to the result of optimisation experiments, $100 \%$ leaching recovery of Ce was achieved under the condition of $6 \mathrm{~N}$ $\mathrm{HCl}, 5 \mathrm{~g} / 50 \mathrm{~mL}$ solid/liquid at $70^{\circ} \mathrm{C}$ and for a duration of 3 hours.

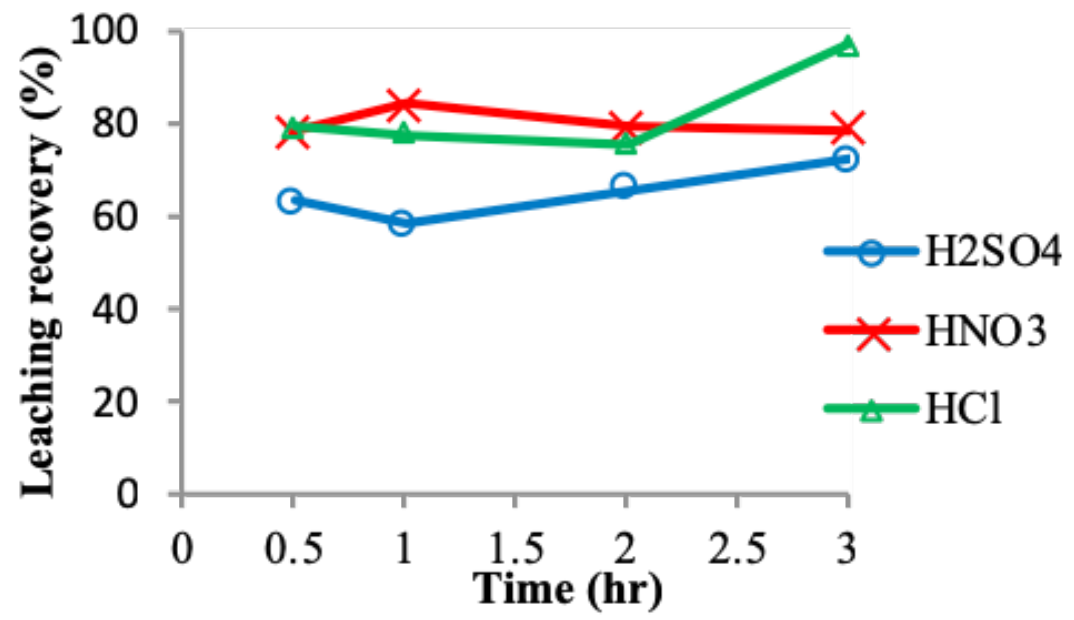

Figure 1. Effect of time on leaching recovery of $\mathrm{Ce}$ with $\mathrm{HCl}, \mathrm{H} 2 \mathrm{SO} 4$ and $\mathrm{HNO} 3$ $\left(1 \mathrm{~N}, 3 \mathrm{hrs}, 70^{\circ} \mathrm{C}, 1 \mathrm{~g} / 50 \mathrm{~mL}\right)$

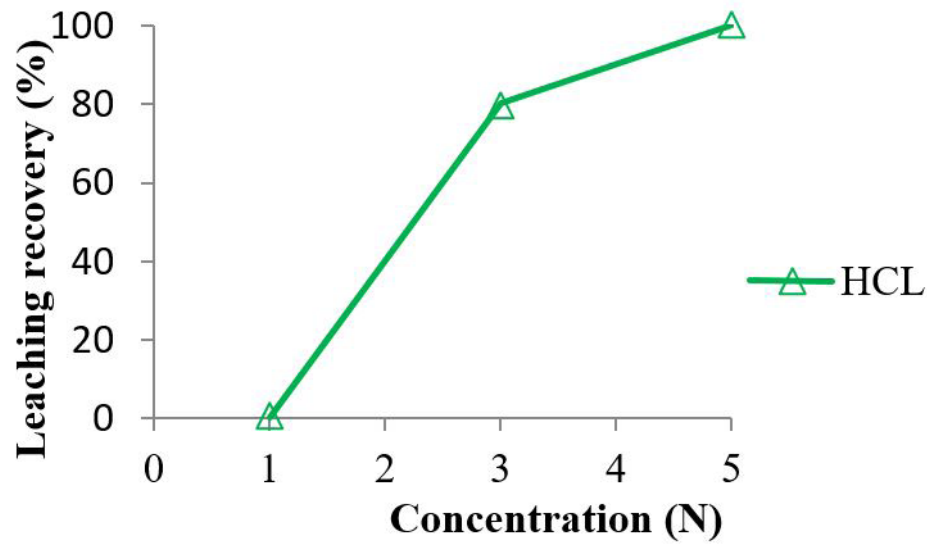

Figure 2. Effect of $\mathrm{HCl}$ leaching reagent concentration on leaching recovery of $\mathrm{Ce}\left(3 \mathrm{hrs}, 70^{\circ} \mathrm{C}\right.$, $5 \mathrm{~g} / 50 \mathrm{~mL})$ 


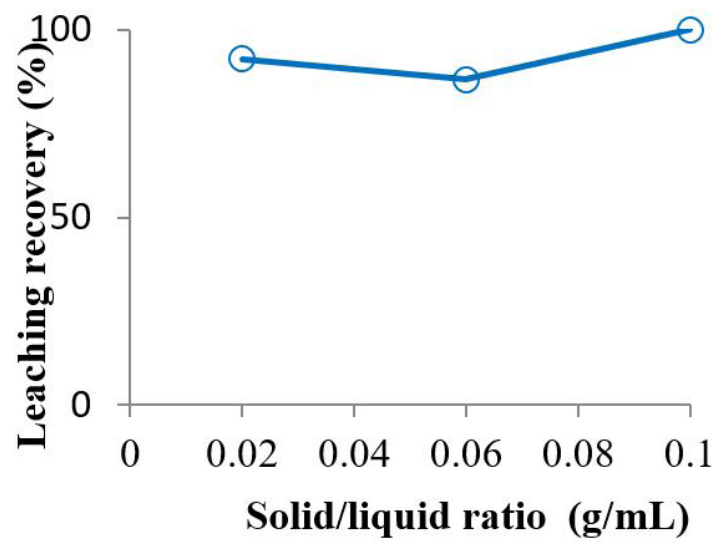

Figure 3. Effect of solid/liquid ratio on the leaching recovery of Ce (3 hrs, $70^{\circ} \mathrm{C}, 6 \mathrm{~N} \mathrm{HCl}$ ).

\section{Precipitation}

The optimal leaching solution was subjected to precipitation method to recover Ce dissolved in the solution by adding precipitation agents, including $\mathrm{NH}_{4} \mathrm{HCO}_{3}, \mathrm{NaHCO}_{3}, \mathrm{Na}_{2} \mathrm{SO}_{4}$, and $\mathrm{K}_{2} \mathrm{SO}_{4}$ in a $1: 1$ ratio. $20 \mathrm{~mL}$ of the leaching solution was treated with the precipitation agents, and the reaction was allowed for 24 $\mathrm{hrs}$ at room temperature. The obtained product at various time intervals of precipitation was analysed by ICP-AES, and the precipitation efficiency was calculated according to Eq (2). The precipitation efficiency of $\mathrm{Ce}$ is presented in Figure 4. The best precipitation recovery of $99.60 \%$ Ce was achieved with $\mathrm{NaHCO}_{3}$ for 24 hours. The $\mathrm{Ce}$ concentration of the obtained precipitation product is determined as $33.09 \%$ by ICP-AES. This means that the Ce grade of the Khuren Khad ore can be enriched from $4.8 \%$ to $33.09 \%$ of precipitation product after the leaching and precipitation recovery processes.

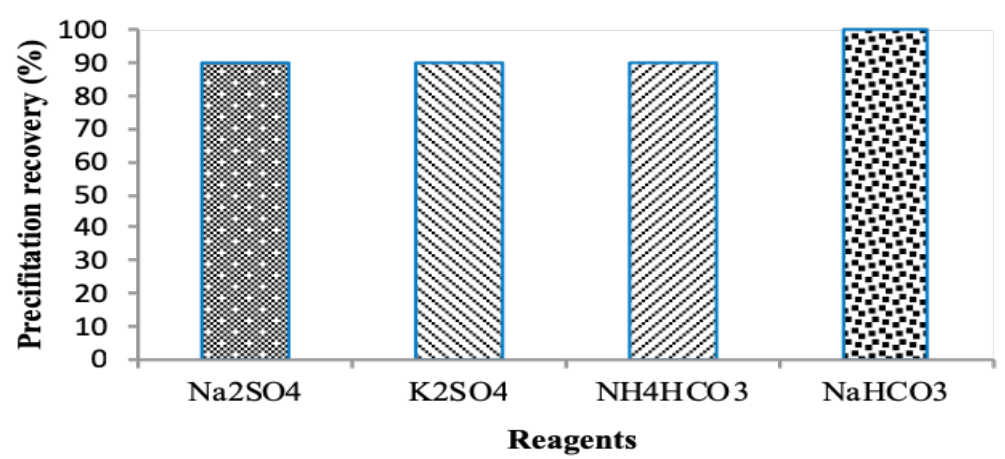

Figure 4. Precipitation recovery of Ce with $\mathrm{NH}_{4} \mathrm{HCO}_{3}, \mathrm{NaHCO}_{3}, \mathrm{Na}_{2} \mathrm{SO}_{4}$, and $\mathrm{K}_{2} \mathrm{SO}_{4}$ at $24 \mathrm{hrs}$

\section{CONCLUSIONS}

The Khuren Khad ore sample was obtained from the Mushgia Khudag deposit, in south Mongolia. The leaching conditions of this collected ore, such as leaching agent, leaching time, the concentration of leaching reagent, temperature and solid/liquid ratio were investigated in this study. Ce contained in the collected ore was $4.8 \%$, which was determined 
by ICP-AES. The optimum leaching result of this study reveals that $100 \%$ Ce leaching recovery can be obtained under a leaching condition of $6 \mathrm{~N} \mathrm{HCl}, 5 \mathrm{~g} / 50 \mathrm{~mL}$ solid/liquid at $700 \mathrm{C}$ for 3 hours. $99.60 \%$ precipitation recovery of $\mathrm{Ce}$ for this obtained optimum leaching solution can be achieved with the addition of $\mathrm{NaHCO}_{3}$ at an interval of 24 hours.
The Ce grade of Khuren Khad ore can be enriched from $4.8 \%$ to $33.09 \%$ of precipitation product after leaching and precipitation recovery processes. This study concludes that leaching and precipitation can be used to concentrate the valuable natural resource of REE.

\section{REFERENCES}

[1] Long, K. R., Van Gosen, B. S., Foley, N. K, and Daniel, C., (2010). Principal Rare Earth Elements Deposits of the U. S.: A Summary of Domestic Deposits and a Global Perspective. U.S. Geological Survey Scientific Investigation Report. 5220.

[2] Janoš, P., Ederer, J., Pilařová, V., Henycha, J., Tolaszb, J., Mildec, D., Opletal, T., (2016). Chemical Mechanical Glass Polishing with Cerium Oxide: Effect of Selected PhysicoChemical Characteristics on Polishing Efficiency. Wear An International Journal on the Science and Technology of Friction, Lubrication and Wear 362-363:114-120. https://doi. org/10.1016/j.wear. 2016.05.020.

[3] Yubo, M., Haiwei, W., Lei, W., Hongyi, L., (2019). Environment-friendly Synthesis of Diethyl Carbonate via Ethyl Carbamate Alcoholysis over Cerium Oxide Catalyst. Journal of Environmental Management 232:952-956. https://doi.org/10.1016/j.jenvman. 2018.12.013.

[4] Goodenough, K. M., Wall, F., Merriman, D., (2018). The Rare Earth Elements: Demand, Global Resources, and Challenges for Resourcing Future Generations. Natural Resources Research 27(2):201-216. http://dx.doi.org/10.1007/s11053-017-9336-5.

[5] Jordens, A., Cheng, Y. P., Waters, K. E., (2013). A Review of the Beneficiation of Rare Earth Element Bearing Minerals. Journal of Mineral Engineering 41:97-114. http://dx.doi. org/10.1016/.j.minIng.2012.10.017.

[6] Andrea, M., (2017). Leaching of Yttrium, Europium and Accompanying Elements from Phosphor Coatings. Hydrometallurgy 176:216-228.

[7] Tan, Q., (2017). Effects of Mechanical Activation on the Kinetics of Terbium Leaching from Waste Phosphors using Hydrochloric Acid. Journal of Rare Earth Element, China, $1-3$.

[8] Stefanie, H., (2017). Leaching of Rare Earth Elements from Fluorescent Powder using the Tea Fungus Kombucha. Waste Management 62:211-221.

[9] Yong, L., (2016). Leaching of Rare Earth Elements from Waste Lamp Phosphor Mixtures by Reduced Alkali Fusion followed by Acid Leaching. Hydrometallurgy, Beijing, China, $1-4$.

[10] Wang, J., (2017). Kinetics Study on the Leaching of Rare Earth and Aluminum from FCC Catalyst Waste Slug using Hydrochloric Acid. Hydrometallurgy 171:312-319.

[11] Edahb, M., (2018). Mineralogical Characterization using QEMSCAN® and Leaching Potential Study of REE within sSilicate oOres: A Case Study of the Matamec Project, Québec, Canada, Journal of Geochemical Exploration, 185:64-73.

[12] Dorozhkin, S. V., (2012). Dissolution Mechanism of Calcium Apatites in Acids: A Review of Literature. World J. Methodol 2:1-17. http://dx.doi.org/10.5662/wjm.v2.i1.1. 
[13] Zhang, J., Zhao, B., Schreiner, B., 2016. Separation Hydrometallurgy of Rare Earth Elements. Springer Int, Switzerland. https://doi.org/10.1007/978-3-319-28235-0.

[14] Lee, C. H., Liao, C. H., Popuri, S .R., Hung, C. E., (2017.) Integrated Process Development for the Recovery of Europium and Yttrium from Waste Fluorescent Powder. Journal of Material Cycles and Waste Management, 19:1235-1243. doi: 10.1007/s10163-016-0515-y.

[15] Taketatsu, T., (1962). Dissolution and An Ion exchange Behaviour of the Rare Earth Elements in Potassium and Ammonium Carbonate Solutions. Bulletin of the Chemical Society of Japan, 35:1573-1576.

[16] TEPA (Taiwan Environmental Protection Agency), (1993). Direction Method Query (in Chinese). Available at: http://www.niea.gov.tw/analysis/method/ListMethod. asp?methodtype $=$ Refuse 